\title{
Squid (Loligo pealei) Giant Fiber System: A Model for Studying Neurodegeneration and Dementia?
}

\author{
PHILIP GRANT, YALI ZHENG, AND HARISH C. PANT** \\ Laboratory of Neurochemistry, National Institute of Neurological Disorders and Stroke, \\ National Institutes of Health, Bethesda, Maryland
}

\begin{abstract}
In many neurodegenerative disorders that lead to memory loss and dementia, the brain pathology responsible for neuronal loss is marked by accumulations of proteins in the form of extracellular plaques and intracellular filamentous tangles, containing hyperphosphorylated cytoskeletal proteins. These are assumed to arise as a consequence of deregulation of a normal pattern of topographic phosphorylation - that is, an abnormal shift of cytoskeletal protein phosphorylation from the normal axonal compartment to cell bodies. Although decades of studies have been directed to this problem, biochemical approaches in mammalian systems are limited: neurons are too small to permit separation of cell body and axon compartments. Since the pioneering studies of Hodgkin and Huxley on the giant fiber system of the squid, however, the stellate ganglion and its giant axons have been the focus of a large literature on the physiology and biochemistry of neuron function. This review concentrates on a host of studies in our laboratory and others on the factors regulating compartment-specific patterns of cytoskeletal protein phosphorylation (primarily neurofilaments) in an effort to establish a normal baseline of information for further studies on neurodegeneration. On the basis of these data, a model of topographic regulation is proposed that offers several possibilities for further studies on potential sites of deregulation that may lead to pathologies resembling those seen in mammalian and human brains showing neurodegeneration, dementia, and neuronal cell death.
\end{abstract}

\section{Introduction}

Cephalopods are a remarkable group of animals with large, complex brains that support a broad range of behav-

Received 1 December 2005; accepted 22 March 2006.

* To whom correspondence should be addressed, at LNC, NINDS, NIH, Bldg 49 Rm 2A28, Bethesda, MD 20892. E-mail: panth@ninds.nih.gov iors, including learning and memory. They exhibit many of the neurobiological paradigms underlying mammalian memory and learning. Octopods, for example, can be trained to identify a variety of visual cues and can even learn behaviorial tricks from one another such as opening jars containing crab prey (Fiorito et al., 1990, Fiorito and Scotto, 1992) Memory and learning can be impaired by lesions to the vertical lobe of the octopus (Fiorito and Chichery, 1995), but to date, no studies of endogenous neurodegenerative disorders in squid or octopus have been published. Nevertheless, cephalopod nervous systems have served successfully for decades in our efforts to understand the basic biology of normal nerve function, from the flow of ion currents in the nerve impulse to the motor systems of axon transport. This store of information acts as a baseline for future research into the origin of the defective nerve function and neuronal cell death responsible for memory loss and dementia in neurodegenerative disorders.

The accumulation of tangles of highly phosphorylated, filamentous cytoskeletal protein complexes in the cell bodies of human brain or spinal cord neurons is a shared pathological feature of many neurodegenerative disorders such as Alzheimer's disease and amyotrophic lateral sclerosis (Goedert, 1999; Fig. 1). Although the specific protein inclusions vary with each disease, these large neuronal aggregates may be responsible for neuron cell death and loss associated with dementia and paralysis, respectively. Among the culprit proteins are tau, neurofilaments, synuclein, and huntingtin, which, through defects in their metabolism, are abnormally processed and misfolded within cell bodies into stable complexes together with kinases and ubiquitins, among other proteins.

How such aggregates arise and how they contribute to neuronal cell death has been the focus of decades of studies. Biochemical, genetic, and molecular biological approaches 
A

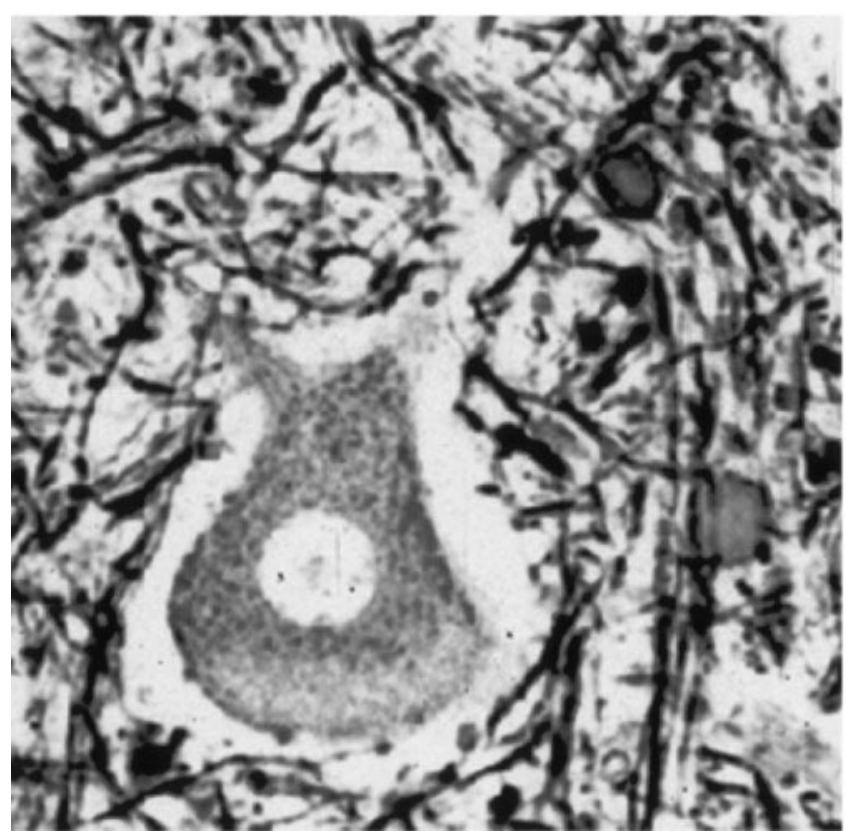

B

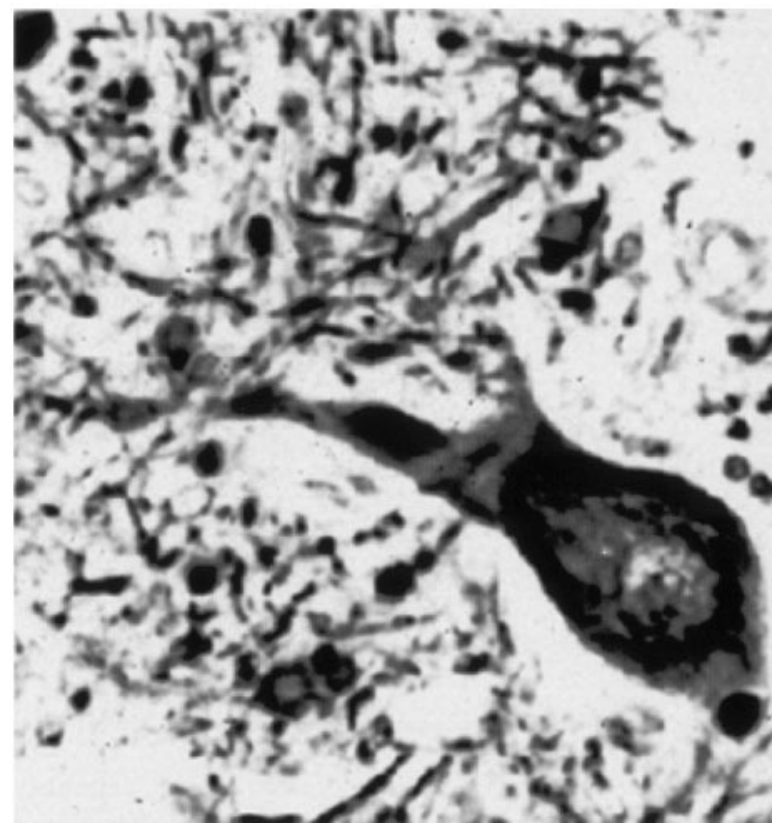

Figure 1. Example of aggregate expression in cervical spinal cord ganglion neurons in amyotrophic lateral sclerosis (ALS). (A) Normal neuron. (B) Neuron showing ALS pathology as a result of deregulated topographic neurofilament phosphorylation. Both expressing an antibody to phosphorylated NF-H.

have furnished an understanding of some of the factors contributing to the pathology. One common thread emerging, however, has been the recognition that the normally tight compartment-specific regulation of post-translational processing (phosphorylation, glycosylation, etc.) and assembly have been compromised in these disorders. For example, neurofilaments, a major cytoskeletal component of large axons, are normally assembled from subunit proteins (NF-L, NF-M, and NF-H). Upon entry into the axon, the latter two are highly phosphorylated in lysine-serine-proline (KSP) repeats in their C-terminal tail domains (Sternberger and Sternberger, 1983; Nixon et al., 1987, 1989; Pant et al., 2000). This results in the formation of sidearms, crossbridges between NFs and microtubules, that create a cytoskeletal scaffold sustaining large axonal diameters (de Waegh et al., 1992; Sanchez et al., 2000). Cell bodies, on the other hand, contain only hypophosphorylated NF proteins. Tail domain phosphorylation does not occur in cell bodies except in pathological situations when KSP repeats are hyperphosphorylated into filamentous aggregates. The factors responsible for topographic regulation/deregulation of NF phosphorylation are not understood, in part because separation of cell bodies from axons in sufficient quantities for biochemical studies is difficult in most mammalian nervous systems. Fortunately, the stellate ganglion of the squid giant fiber system, which shares many neuronal properties with mammalian systems, including a robust NF metabolism, is readily separated into giant cell bodies and pure axoplasm in quantities sufficient for diverse biochemical studies. This system has been the focus of our studies for several years as we attempted to sort out the factors underlying the compartmental-specific patterns of neurofilament phosphorylation.

\section{The Squid Giant Fiber System}

It was J. Z. Young who first described the structure and origin of the giant fiber system of the squid Loligo (Young, 1939). Since then a vast literature on the physiology, behavior, and biochemistry of the giant fiber system has been published, including the Nobel-prize-winning work of Hodgkin and Huxley (see also, Gilbert et al., 1990). The jet propulsion locomotory behavior of this remarkable organism depends upon the signaling evoked by a system of giant neurons beginning with two large "command neurons" in the brain. The command neurons integrate most sensory input to transmit excitatory impulses to the dorsal stellate ganglia and giant axons that innervate the muscles of the mantle. The diameter of the giant axon can vary between 300 and 800 micrometers (Adelman and Gilbert, 1990), and its length may extend several centimeters depending on species and size of the animal. Accordingly, ganglia and giant axons are easily dissected from the mantle and prepared for electrophysiological and biochemical studies or for studies of mechanisms of axon transport (Fig. 2). The giant axon owes its large size to the fact that it arises as a 


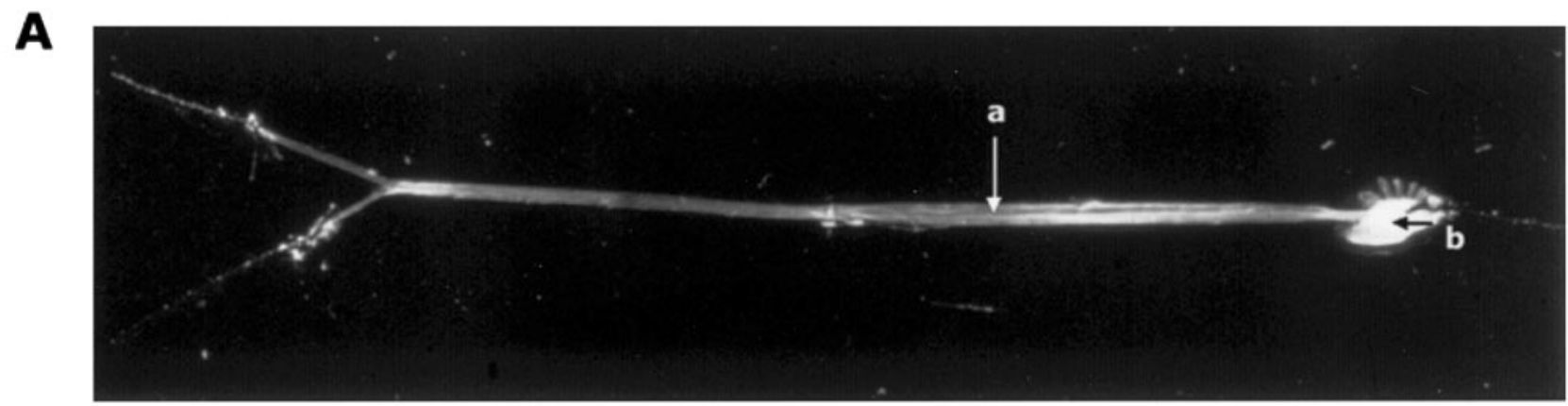

B

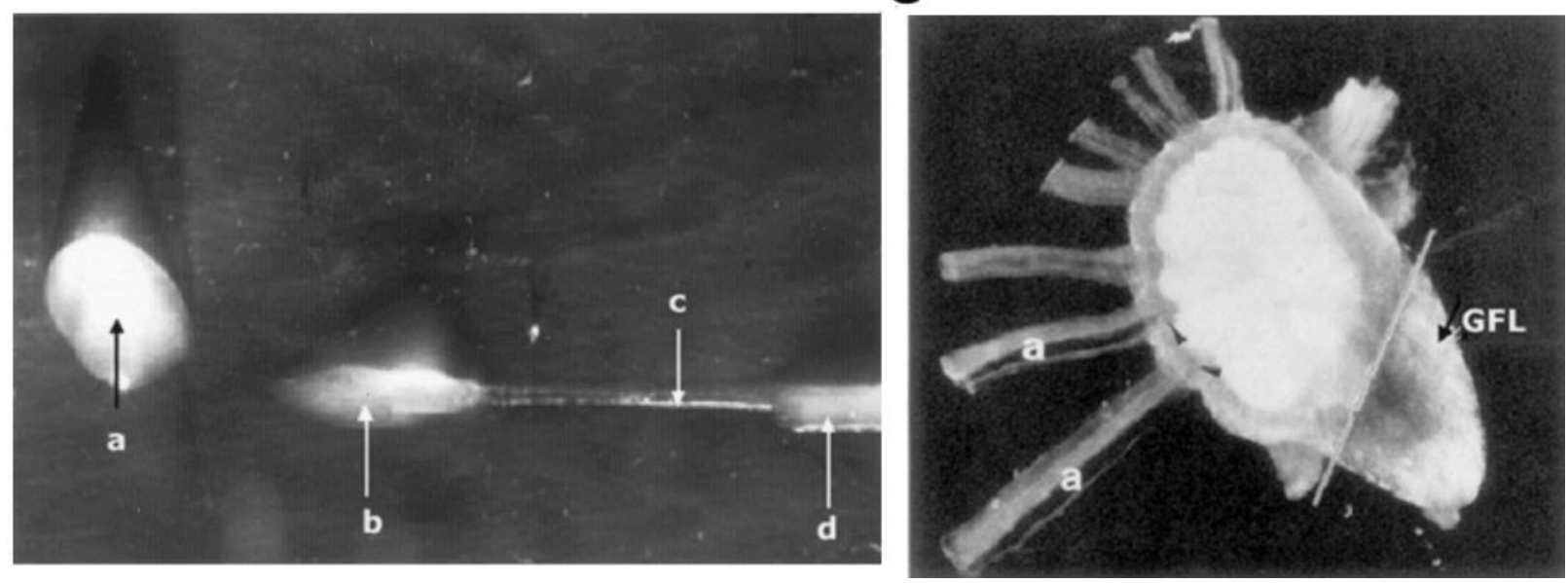

Figure 2. Stellate ganglion and giant axon isolated from squid (Loligo pealei). (A) Intact preparation showing giant axon (a) in its sheath and stellate ganglion (b) with stubs of other giant axons. About $2 \times$ normal size. (B) Collection of pure axoplasm: (a) Droplet of axoplasm extruded from giant axon; (b) droplet squeezed from axon, leaving empty collapsed sheath (c); (d) intact axon with sheath. (C) Isolated stellate ganglion showing site of cut to collect giant fiber lobe cell bodies. "a" are giant axons.

fusion of many individual axons from the large neurons $(25-40 \mu \mathrm{m})$ of the giant fiber lobe (GFL). About 3-10 $\mu \mathrm{l}$ of pure axoplasm, uncontaminated by sheath or glial cells, can be collected from a single giant axon, depending on size, making it possible to collect up to $300-1000 \mu \mathrm{l}$ of axoplasm from 10 squid ( 2 axons per squid). Together with GFL cell bodies dissected from the same stellate ganglia, the two tissue preparations can be compared biochemically. Using this system, we have studied the factors regulating the topographic phosphorylation of NF proteins.

\section{Squid Neurofilament Proteins}

Squid neurofilaments in the giant axon, like those in mammalian axons, contribute to the large axon caliber responsible for rapid conduction velocity, a property essential to the jet propulsive function of mantle muscle. Neurofilaments, together with microtubules and associated proteins, are organized into a hexagonal array that makes up a threedimensional cytoskeletal network in the giant axon (Metuzals and Izzard, 1969; Hodge and Adelman, 1980;
Martin et al., 1990). NFs make up about $13 \%$ of total axoplasm protein (Brown and Lasek, 1990) and consist of three subunit proteins - a large, highly phosphorylated NF220 and two smaller subunits, NF60 and NF70. These have been cloned and shown to arise by alternative splicing from a single gene, in contrast to the three independent genes that code for mammalian NF subunits (Szaro et al., 1991; Way et al., 1992). Biochemically and immunocytochemically, the NF-220 is phosphorylated only in the axon, whereas a non-phosphorylated NF-180, together with NF60/70, is detected in the perikarya of the stellate ganglia (Tytell et al., 1990; Cohen et al., 1987). Phosphorylation occurs predominantly on the multiple K/RSP, SAR/K, and SEK/R repeat sites (approximately 47) on the C-terminal tail of the NF220 subunit (Jaffe et al., 2001). This topographic pattern of NF phosphorylation resembles that seen in mammalian neurons, with the axon as the principal site of NF phosphorylation, as described above.

A comparison of kinase assays of axoplasm and GFL lysates illustrates the differences in compartment activities. 
Western blot analysis of GFL and axoplasm lysates indicate that, except for NF-220, cytoskeletal protein substrates are indeed present in both compartments (Fig. 3) (Grant et al., 1999). Although the protein expression profiles of axoplasm and GFL are similar (Fig. 3A, left), the endogenous kinase activity of axoplasm is significantly higher than in the GFL (Table 1), with NF220 and other proteins highly phosphorylated, as seen in the autoradiograph at the right of Figure 3A. The GFL lysate exhibits fewer phosphorylated proteins, with most phosphorylation seen in low-molecular-weight bands (asterisk). Although cell body tubulin is moderately phosphorylated, the NF220 is not, in spite of the fact that the overall phosphorylation activity is similar in both compartments. Although this suggests that kinases are inactive within cell bodies, equivalent phosphorylation of exogenous substrates such as histone and casein (Fig. 3B, right, and Table 1) indicates that kinases are indeed present and equally active in the GFL lysate.

Significantly, however, endogenous higher molecular weight proteins are much more robustly phosphorylated within the axoplasm (Fig. 3A, right), suggesting that cell bodies and axoplasm may not share the same set of kinases and/or phosphatases.

\section{Kinases in Axoplasm and GFL Are Similar}

The multiple phosphate acceptor sites in NF proteins invite a sequential pattern of phosphorylation by a number of synergistically interacting kinases (Roach, 1991). In fact, NF subunit proteins are phosphorylated at different ser/thr sites within head and tail domains by a variety of kinases. These include second-messenger-regulated kinases such as PKA, PKC, and CAMKII (Sihag et al., 1988; Sihag and Nixon, 1989; Dosemeci et al., 1990; Dosemeci and Pant, 1992), preferentially phosphorylating head domain sites; second messenger independent kinases, CKI, CKII (Floyd et al., 1991); GSK3 (Guidato et al., 1996) and prolinedirected kinases Erk1/2, JNK, SAPK, cdc-2, cdk5, among others (Sun et al., 1996; Giasson and Mushynski, 1997; Veeranna et al., 1998; Li et al., 1999). The C-terminal tail domain KSP repeats in squid NF-H 220 are the principal targets of phosphorylation by the proline-directed kinases.

A Western blot analysis of kinases expressed in GFL cell bodies and axoplasm indicates that qualitatively at least, the two compartments reveal a similar array of kinases (Grant $e t$ al., 1999). Some kinases such as CKI are intimately bound to the NF preparation extracted from axoplasm, suggesting it may phosphorylate ser/thr sites in the glutamine-acid-rich region of the NF tail domains and play an important role in regulating axon transport (Floyd et al., 1991). Nevertheless, both CKI and CKII are expressed in each compartment (Grant et al., 1999). With respect to head-domain-specific kinases, such as CAMKII and PKA, quantitative differences have been demonstrated, with the cell body compartment exhibiting significantly higher endogenous kinase activities. These kinases phosphorylate specific NF head domain sites that, when phosphorylated, prevent filament assembly (Hisanaga and Hirokawa, 1990; Sihag and Nixon, 1989, 1990, 1991). The proline-directed kinases, cdc2-like (cdk5), Erk1/2, GSK3, are also present at equal expression levels in each compartment. Since no significant qualitative differences in the distribution of kinases are evident, how then can we explain the profound difference in overall pattern of endogenous protein phosphorylation between cell bodies and axoplasm?

\section{Axonal and Cell Body Multimeric Complexes of Cytoskeletal Proteins and Kinases Are Different}

To further explore topographic regulation of phosphorylation, the presence of a cdc2-like kinase in the squid giant fiber system was investigated by P13 affinity chromatography. P13, with a high binding affinity to cdc2 kinases, has been used to extract cdc2 and associated proteins from mitotic cells (Brizuela et al., 1987; Draetta et al., 1987). We have used this procedure to study cdc2-like kinases in axoplasm and cell body, which when combined with Western blot analysis and kinase assays, will make it possible to compare the P13 multimeric complexes characteristic of each compartment (Takahashi et al., 1995; Grant et al., 1999). Although NF220 was absent from the cell body lysates, Western blots of each compartment were similar with respect to other cytoskeletal proteins (tubulin, actin, NF60/70) and a set of kinases. The P13 multimeric complexes extracted from these lysates were dramatically different, however; the P13 axoplasm complex exhibited 6 to 20 times more endogenous and exogenous phosphorylation activities (Fig. 4), contained more cytoskeletal proteins and kinases, and expressed a qualitatively different cdc2-like kinase epitope. The axonal multimeric complex, transported in the growing squid axon, undergoes extensive phosphorylation.

It is well established that most kinases (proline-directed and non-proline-directed) copurify with their cytoskeletal substrates as multimeric complexes. PKA, PKC, and CKI copurify with NFs (Sihag et al., 1988; Floyd et al., 1991; Dosemeci and Pant, 1992), while proline-directed kinases such as cdk 5 and Erk1/2 coassemble with NFs, tubulins, and tau (Vallano et al., 1986; Veeranna et al., 2000). In cell bodies, where cytoskeletal subunits and kinases are newly synthesized, before secondary processing occurs, the multimeric complexes assembled may differ significantly from those assembling in the axon after the kinases and substrates have been partially processed prior to transport. As a result, the availability of phosphate acceptor sites, such as those on C-terminal tail domains of NF proteins, may only become accessible within the three-dimensional structure of a growing, stable axonal lattice. For example, although GFL and 


\section{A}
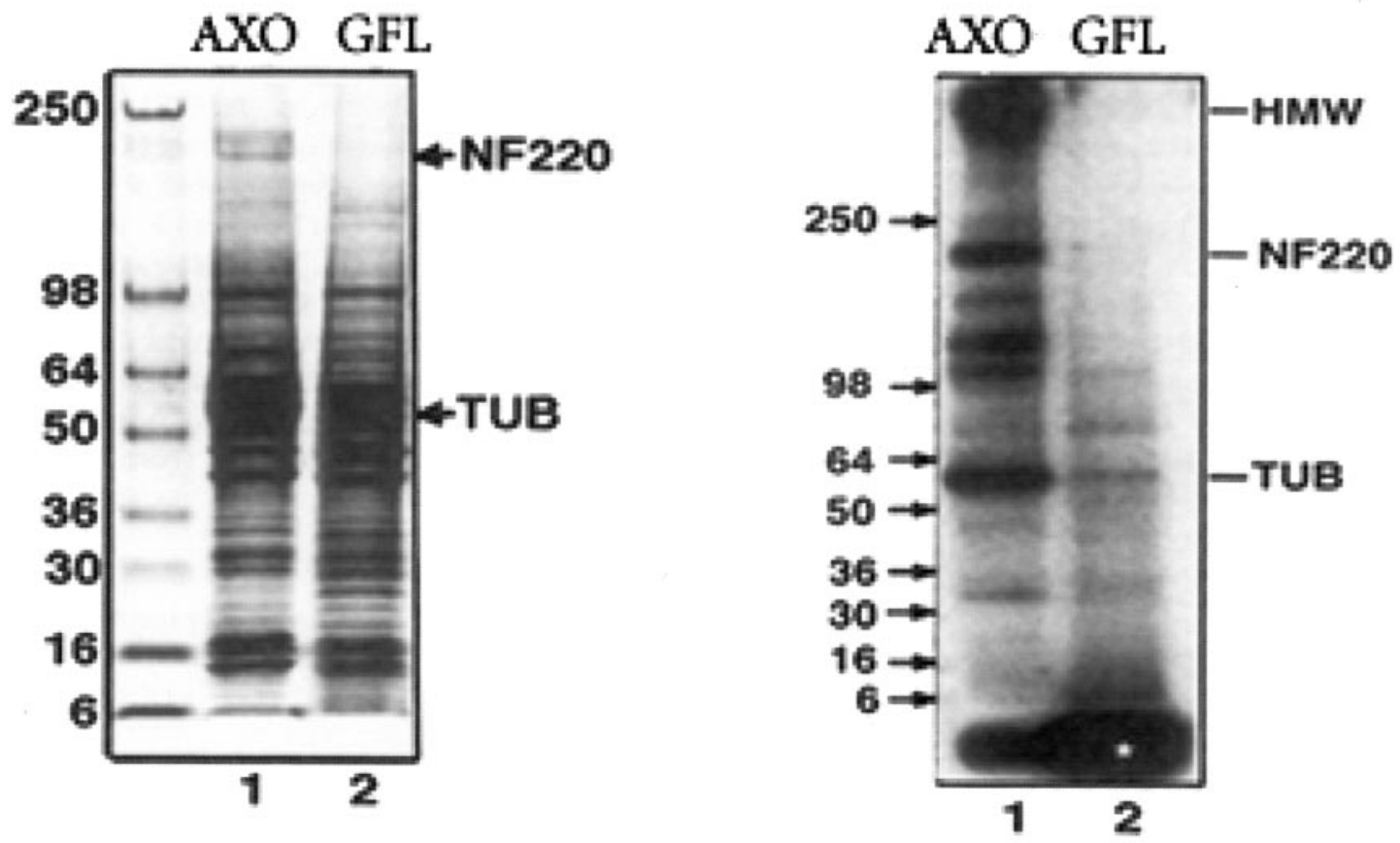

B

\section{Stain}
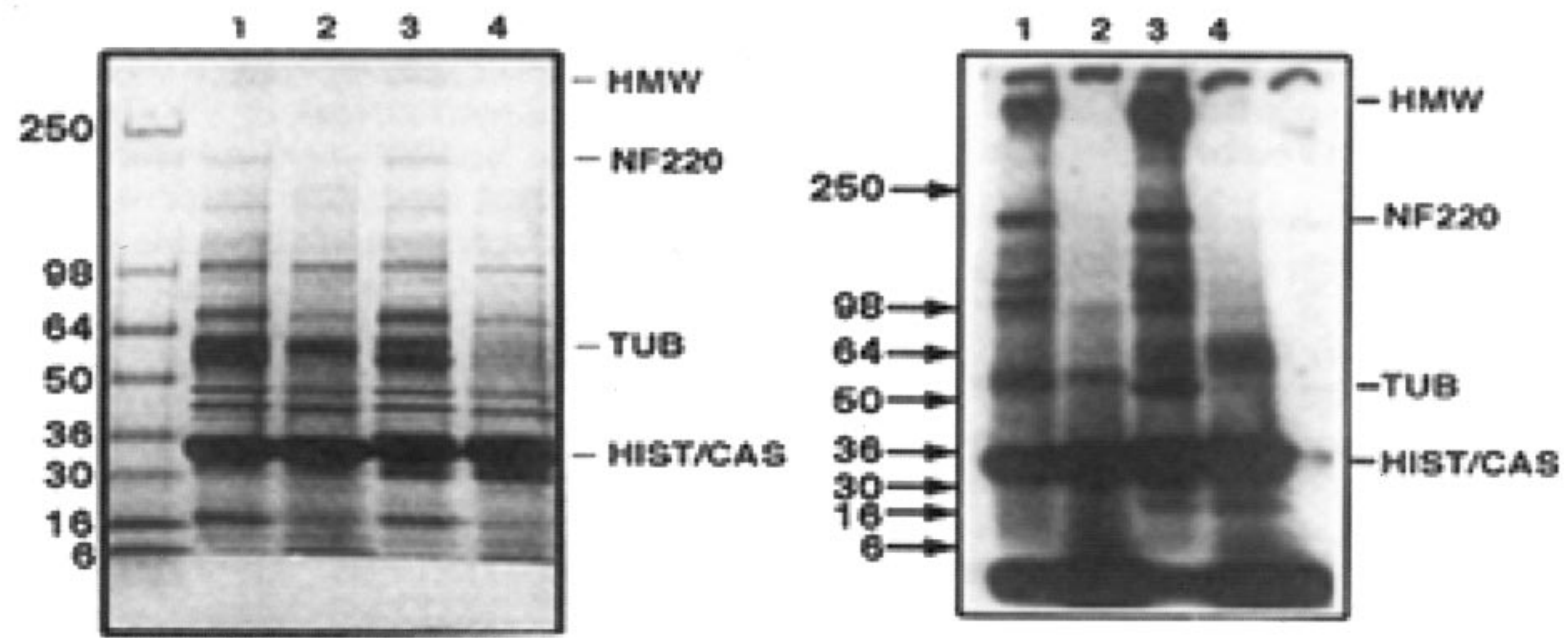

Figure 3. Comparison of kinase activities in lysates of axoplasm and giant fiber lobe (GFL). (A) Left, Coomassie-stained gel showing similarity of protein expression in axoplasm and GFL, except for expression of NF220 in axoplasm. Right, autoradiograph showing robust phosphorylation of proteins in axoplasm with virtually no high-molecular-weight bands phosphorylated in GFL. Instead, there are high levels of phosphorylation at the advancing front (asterisk). (B) Left, Coomassie-stained gel showing protein profile in lysates containing exogenous substrates histone and casein. Lane 1, axoplasm plus casein; lane 2, GFL plus casein; lane 3 , axoplasm plus histone; lane 4, GFL plus histone. Note similarity in expression pattern. Right, autoradiograph showing equivalent phosphorylation of exogenous substrates casein and histone by axoplasm (lanes 1 and 3 ) and GFL (lanes 2 and 4), respectively. Even under these conditions, axoplasm reveals intense phosphorylation of most proteins. HMW = high-molecular-weight. NFH 220 complex. 
Table 1

Comparison of total kinase activities (in pmol/ $\mu \mathrm{g} P \times 10^{-4}$ ) of axoplasm and giant fiber lobe (GFL) lysates

\begin{tabular}{lrcc}
\hline \hline Tissue & End & Hist & \multicolumn{1}{c}{ Cas } \\
\hline AXO & $10.2 \pm 3.7$ & $11.6 \pm 3.8$ & $6.0 \pm 6.0$ \\
GFL & $5.9 \pm 3.1$ & $15.2 \pm 4.9$ & $12.6 \pm 10.0$ \\
\hline
\end{tabular}

Although endogenous activity of axoplasm is about $2 \times$ that in GFL, the phosphorylation of exogenous substrates is about the same for histone and casein in the GFL, suggesting that kinases are indeed present and active in the GFL. End = endogenous activity; Hist = activity with histone as substrate; Cas $=$ activity with casein as substrate.

axoplasm lysates expressed CKI and CKII, only the axonal P13 complex expressed CKI, a result that correlated with its high level of casein phosphorylation. This is consistent with previous observations of the high affinity of CKI to the axonal NF preparations and the possible role of CKI in regulation of slow axonal transport of NFs. Moreover, electron microscopy studies of filamentous structures in cell body and axoplasm reveal differences reflecting the phosphorylation-driven sidearm extension of the NF220 C-terminal tail domains as NF polymers slowly migrate down the axon (Cohen et al., 1987). The NF subunits predominate in cell body NFs in a network of smooth filaments without sidearms. In axoplasm, however, NFs exhibited a more complex beaded structure arising from accumulations of fixed phosphorylated NF220 sidearms associated with kinases and other proteins.

Macromolecular complexes of kinases and scaffolding proteins are common in signal transduction systems (Robinson and Cobb, 1997), or in integrin-based focal adhesion complexes (Miyamoto et al., 1995). Specific targeting proteins, as part of such complexes, localize kinases to different cellular compartments or organelles evoking activity (Faux and Scott, 1996). A mammalian scaffold protein, AKAP79, acts as a platform for the assembly of PKA, PKC, and calcineurin, a complex that is targeted to neuronal postsynaptic membranes where they colocalize with substrates (Klauck et al., 1996).

Such localization mechanisms may account for the perikaryal and axonal differences in phosphorylation activity characteristic of the squid giant fiber system. Does this, however, fully explain topographic regulation? It may be a partial answer, since the role of phosphatases in regulating phosphorylation has not been explored.

\section{Phosphatases as Regulators of Topographic Phosphorylation}

In an early study of kinase phosphorylation of squid NFs, preliminary evidence was obtained suggesting that the low level of endogenous NF phosphorylation by GFL extracts was due to the presence of an active inhibitor. GFL extracts added to an active axonal-derived NF preparation dramatically inhibited phosphorylation (Pant et al., 1986). Heating the GFL lysate eliminated the inhibitory effect, suggesting that an enzyme-possibly a phosphatase-might be responsible. Using phosphatase inhibitors, okadaic acid for the ser/thr phosphatases, and vanadate for specific inhibition of tyrosine phosphatases (Brautigan and Shriner, 1988; Gordon, 1991), phosphatase activities were compared in extracts from both compartments. Endogenous phosphorylation of GFL lysates was insensitive to okadaic treatment, suggesting the relative inactivity of ser/thr phosphatases (Grant and Pant, 2004). Surprisingly, ser/thr phosphatases seem to be more abundant in axoplasm, suggesting that their activities may be inhibited within the multimeric complex. However, the response to vanadate points to the GFL cell bodies as relatively enriched with tyrosine phosphatases and tyrosine kinases compared to axoplasm, particularly those associated with a membrane fraction. Localization of tyrosine kinases and phosphatases within membranes of the cell body compartment may implicate signal transduction pathways as additional negative regulators of cytoskeletal protein phosphorylation. Western blot analysis, using mammalian-derived antibodies specific for catalytic groups on mammalian and human phosphatase epitopes, did reveal that the GFL membrane fraction expressed several tyrosine phosphatases at higher levels together with tyrosine phosphatase assays (Grant and Pant, 2004) (Fig. 5). Can such differences in tyrosine phosphatase activities account for topographic regulation of phosphorylation? If so, how?

If we assume that the equilibria between kinase and phosphatase activities within compartment-specific multi-

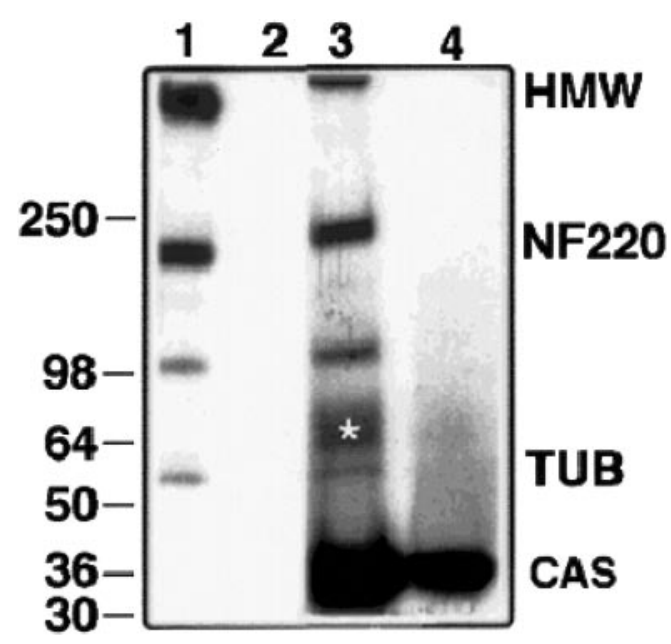

Figure 4. Autoradiographs showing a comparison of phosphorylation activities in PI3 multimeric complexes extracted from axoplasm (lanes 1 and 3) and GFL, (lanes 2 and 4). Lane I, endogenous activity in axoplasm; lane 2, endogenous activity in GFL; lane 3, PI3 axoplasm activity in the presence of exogenous casein; lane 4, PI3 GFL activity in the presence of casein. HMW $=$ high molecular wt. NF220 complex. 


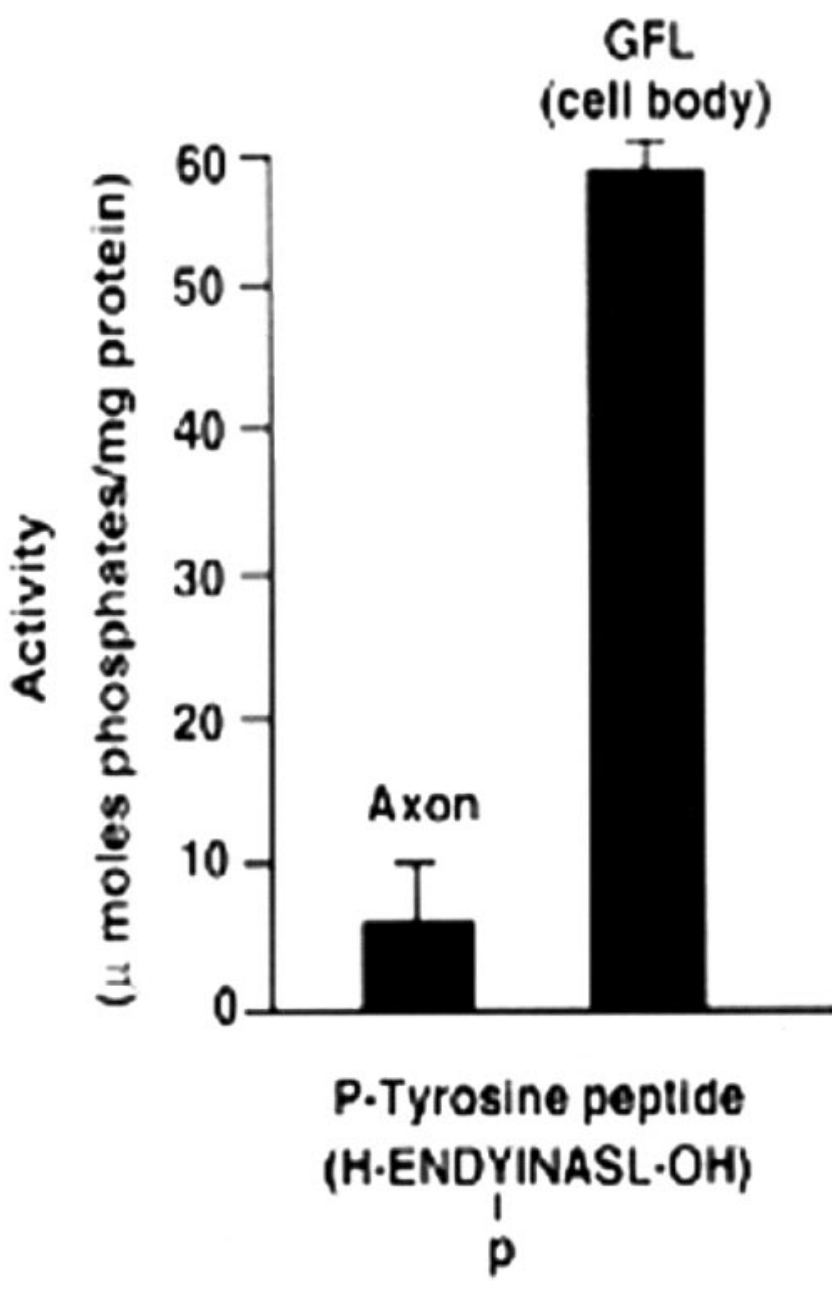

Figure 5. Tyrosine phosphatase activities (specific activity) in membrane fractions of whole axons and giant fiber lobe cell bodies, using a specific phosphopeptide substrate and a Malachite green colormetric assay. Cell body lystaes express significantly higher activities.

meric complexes are crucial to the endogenous patterns of cytoskeletal protein phosphorylation, then changes in the their respective three-dimensional configurations may facilitate shifts in equilibria and the accessibility of phosphate acceptor sites. The occurrence of such structural changes is suggested by the active phosphorylation response of axonal extracts to changes in salt concentration while GFL extracts remain unaffected (Fig 6). Endogenous kinase activity of axonal extracts peaks at $100 \mathrm{~m} M$ salt, then declines at higher salt concentrations. On the other hand, with an exogenous substrate such as histone, no robust salt effect is noted in axoplasm or in GFL extracts, suggesting that high salt readily exposes acceptor sites on endogenous substrates in the axonal multimeric complex. Or, on the other hand, phosphatases may be more effectively dissociated from the axoplasm complex in the presence of high salt, thereby shifting the equilibria towards more active phosphorylation. Because the nature of these complexes is unknown, we can only conclude that the differential phosphorylation response to salt corroborates the existence of compartment-specific phosphorylation complexes.

Can the higher tyrosine phosphatase and tyrosine kinase activities of the cell body membrane fraction provide an alternative explanation for topographic regulation? Since these enzymes target tyrosine sites rather than ser/thr sites, it is unlikely that they directly affect substrate phosphorylation, but they may have some alternative regulatory role that affects the activity of proline-directed kinases such as cdc2, cdk5, and Erk1/2. These latter proline-directed kinases phosphorylate the many KSP repeat motifs in the C-terminal tail domain of the NF220. The absence of NF220 phosphorylation in cell bodies suggests that proline-directed kinases may be down-regulated, perhaps by interaction with signal transduction pathways. For example, kinases in the MAP kinase signal transduction pathway, such as Erk1/2, are activated by MEK1 phosphorylation at residues T183 and Y185, respectively, and inactivated by dephosphorylation by ser/thr phosphatases, tyrosine-specific phosphatases, or dual-acting phosphatases (Cohen, 2000; Keyse, 2000). The higher levels of tyrosine phosphatase activity in cell bodies may inactivate Erk1/2 more effectively than in the pure axoplasm. Alternatively, the higher tyrosine phosphatases in cell body membranes may down-regulate the receptor signaling, thereby diminishing Erk1/2 activity. To investigate this possibility, we compared the expression of activated Erk1/2 in GFL cell body lysates with axoplasm lysates by Western blotting only to find, surprisingly, that the pErk $1 / 2$ activities were similar (unpubl. data). Interpretation of this result is difficult since activated Erk1/2 within perikarya is probably segregated into separate nuclear and cytoplasmic compartments, and only in the latter can it associate with its cytoskeletal protein substrates. In pure axoplasm, however, all activated Erk1/2 is cytoplasmic, able to interact directly with all substrates. Further studies are necessary to understand the relationship between the MAP kinase pathway and its regulation by tyrosine phosphatases in cell bodies and axoplasm. It is noteworthy that active MAP kinase in the axonal compartment seems to be important in facilitating NF anterograde transport in cultured neuroblastoma cells (Chan et al., 2004), raising the possibility that $\mathrm{C}$-terminal tail domain phosphorylation drives NF transport. (See section on axon transport below.)

\section{A Model of Topographic Regulation of NF Protein Phosphorylation in the Squid Giant Fiber System}

An appraisal of the above studies, including data from a large literature on mammalian neurofilament phosphorylation, provides the basis for a working model of NF synthesis and processing in the squid giant fiber system (Fig. 7). Transcription and translational regulation of NF gene expression are not dealt with in the model; rather the focus is 
A
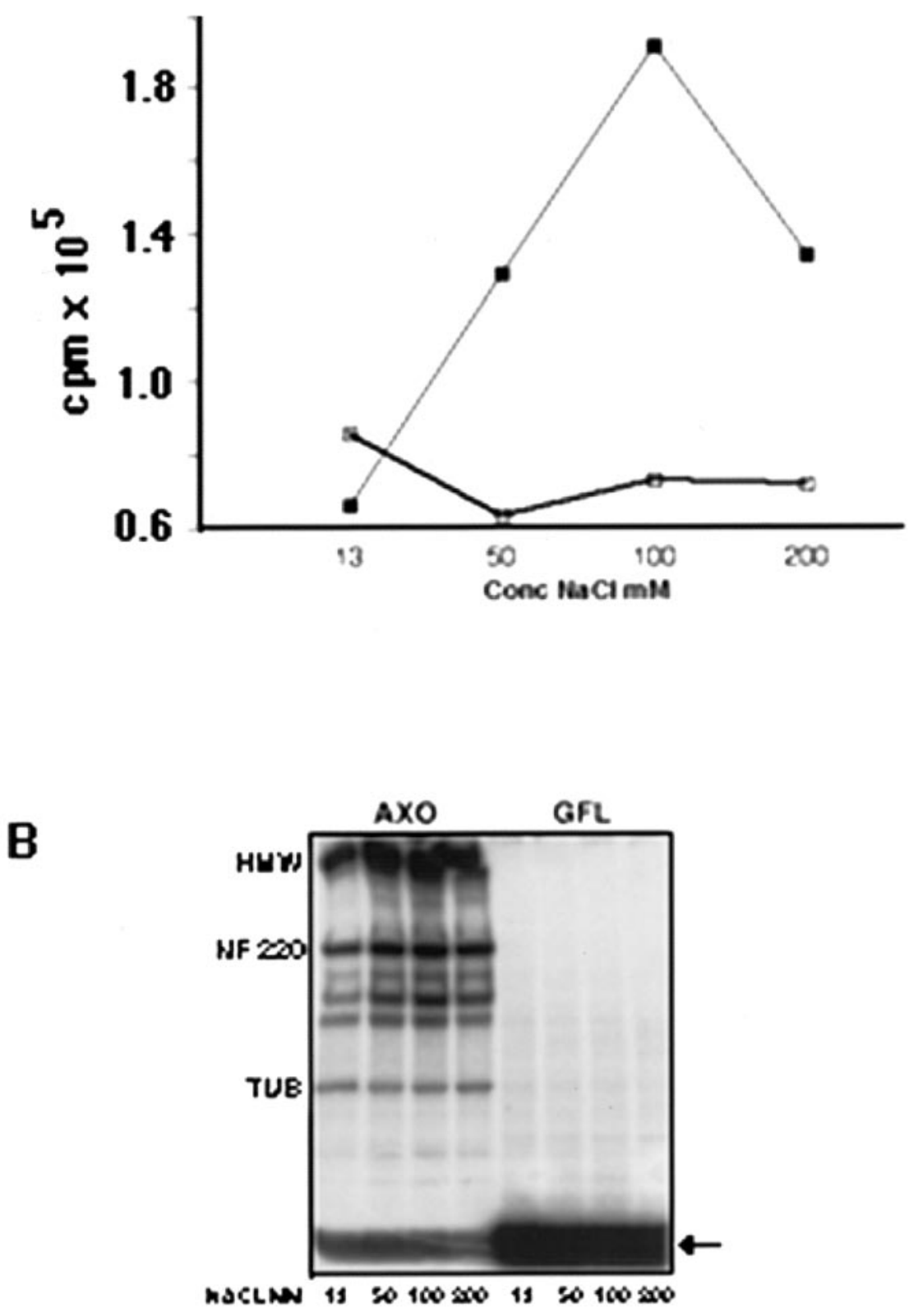

Figure 6. Effect of varying concentrations of $\mathrm{NaCl}$ on endogenous kinase activities of axoplasm and giant fiber lobe (GFL) extracts in the presence of phosphatase inhibitors. (A) Graph showing the response of axoplasm extracts to increasing concentrations of $\mathrm{NaCl}$, with peak activity at $100 \mathrm{mM}$, while GFL lysates exhibit no change over the range of concentrations. (B) Autoradiograph of gels prepared from above lysates, showing the dramatic differences in sensitivity of axoplasm and GFL extracts. Arrow points to low-molecular-weight region where GFL activity is almost exclusively expressed. HMW = high-molecular-weight, NF220 complex.

on post-translational processing, NF assembly, and transport from the cell body compartment to the axon. It is assumed that all "players" in these processes-kinases, phosphatases, regulators and cytoskeletal substrates-are synthesized in cell bodies of the GFL, simultaneously with the initial processing events. According to the model, polymerization of NF monomers and oligomers is transiently affected by phosphorylation of NF60-kd and NF 180-kd head domain sites by PKA, PKC, or both. A cell-bodyspecific multimeric complex of "incomplete" filaments and dense bodies is assembled with little or no evidence of sidearm formation (Cohen et al., 1987). The complex consists of substrates; kinases, including proline-directed kinases (Erk1/2, cdc2-like kinase, SAP kinase); and phospha- 


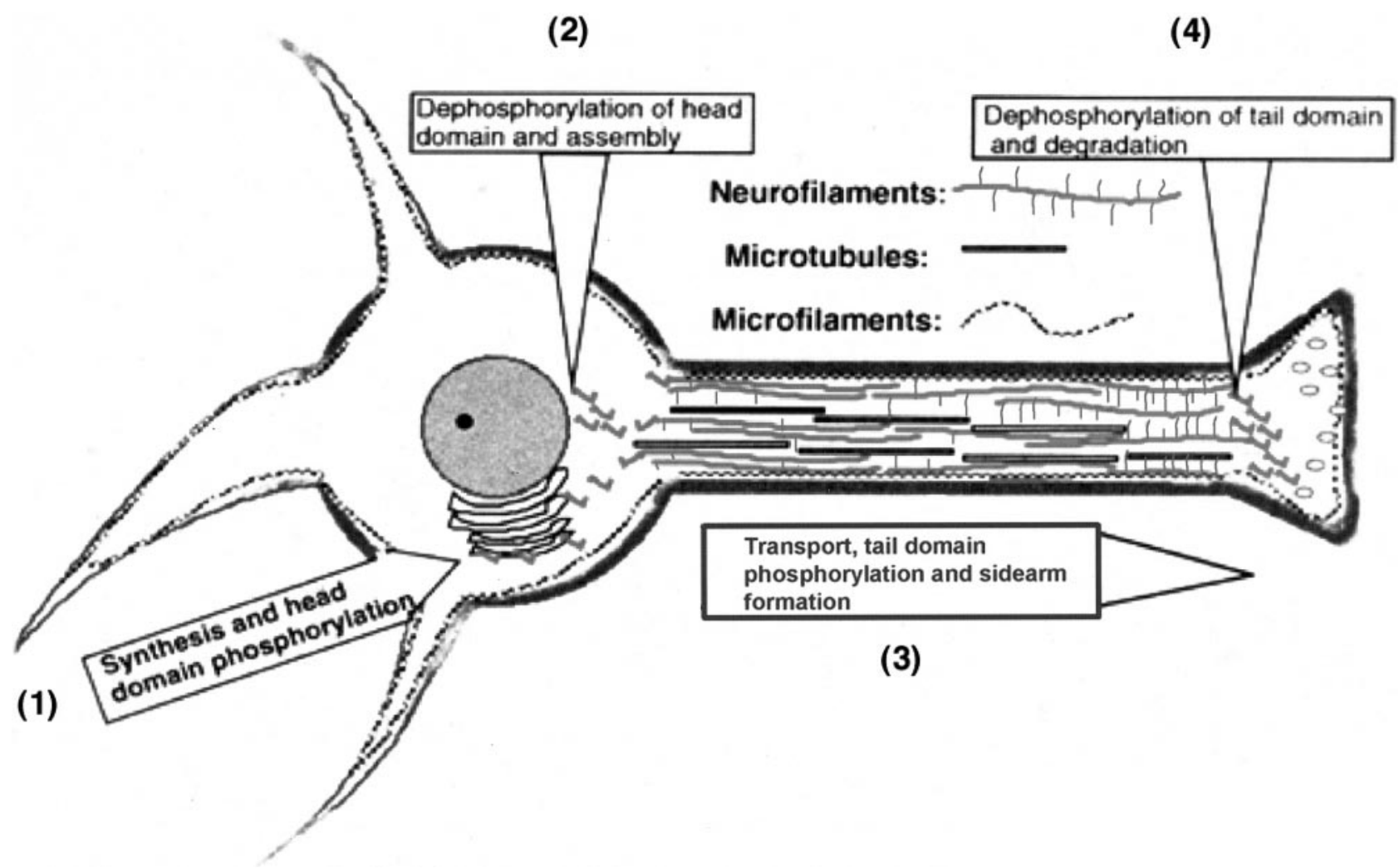

Figure 7. Model of normal topographic regulation of neurofilament (NF) phosphorylation from cell body to synaptic region. (1) Synthesis of NF monomers in cell body, coupled to head domain phosphorylation by PKA, PKC, and/or CAMKII, and partial assembly with kinases and phosphatases into a relatively inactive multimeric complex because of tyrosine phosphatase activity, and/or because specific motifs for proline-directed kinases are inaccessible for phosphorylation by the 3-D configuration of the complex. (2) Axon hillock region in which ser/thr phosphatases dephosphorylate NF head domains and promote NF assembly and association with microtubule (motors?) to form an activated axon transport complex. (3) Within the axon complex, prolinedirected kinases (Erk1/2, SAPK, Cdc2-like kinases) along with CK1 and GSK3 progressively phosphorylate newly accessible tail domain phosphate acceptor sites, including the numerous KSP repeats, resulting in sidearm extension and formation of a stable cytoskeletal lattice. As the complex is slowly transported, small NF oligomers are progressively added to the growing NF-core complex, where they are phosphorylated. (4) Finally, at the axon tip near the synapse, ser/thr phosphatases are activated dephosphorylating tail domain sites, followed by disassembly and degradation of the complex by calpains.

tases. Because of the three-dimensional configuration of the complex, the numerous phosphate acceptor sites in the C-terminal tail domain of NSF 180 are inaccessible to these kinases. Accordingly, they are not phosphorylated. Furthermore, the higher levels of tyrosine phosphatase may also contribute to an inactive complex by down-regulating the activity of MAP kinases within the complex. Under these conditions, the non-phosphorylated NFs readily associate with microtubules within the axon initial segment for transport within the axon. In this region, serine/thr phosphatases are subsequently activated and NF head domain sites are dephosphorylated, thereby promoting more stable polymerization, changes in confirmation of the multimeric complex, and exposure of tail domains to proline-directed kinases. As polymeric NFs are slowly transported within the axon, proline-directed kinases sequentially phosphorylate tail do- main KSP repeat sites; this promotes further extension of sidearms and crossbridge formation between NFs and microtubules, which assemble into a stable cytoskeletal core. Inasmuch as the giant axons grow continuously throughout the one-year life of the squid, axon growth is dynamic, with a crossbridged cytoskeletal core moving slowly, if at all, surrounded by more soluble tubulins and smaller moving $\mathrm{NF}$ polymers that become integrated into the expanding cytoskeleton (Galbraith et al., 1999). Sustaining this dynamic process of assembly and transport is a more robust phosphorylation complex of active kinases and phosphatases to ensure continuous growth in length and diameter of the underlying cytoskeletal network.

Very few details of this model have been experimentally studied. One approach recently taken is to examine the role of transient PKA head domain phosphorylation in the 

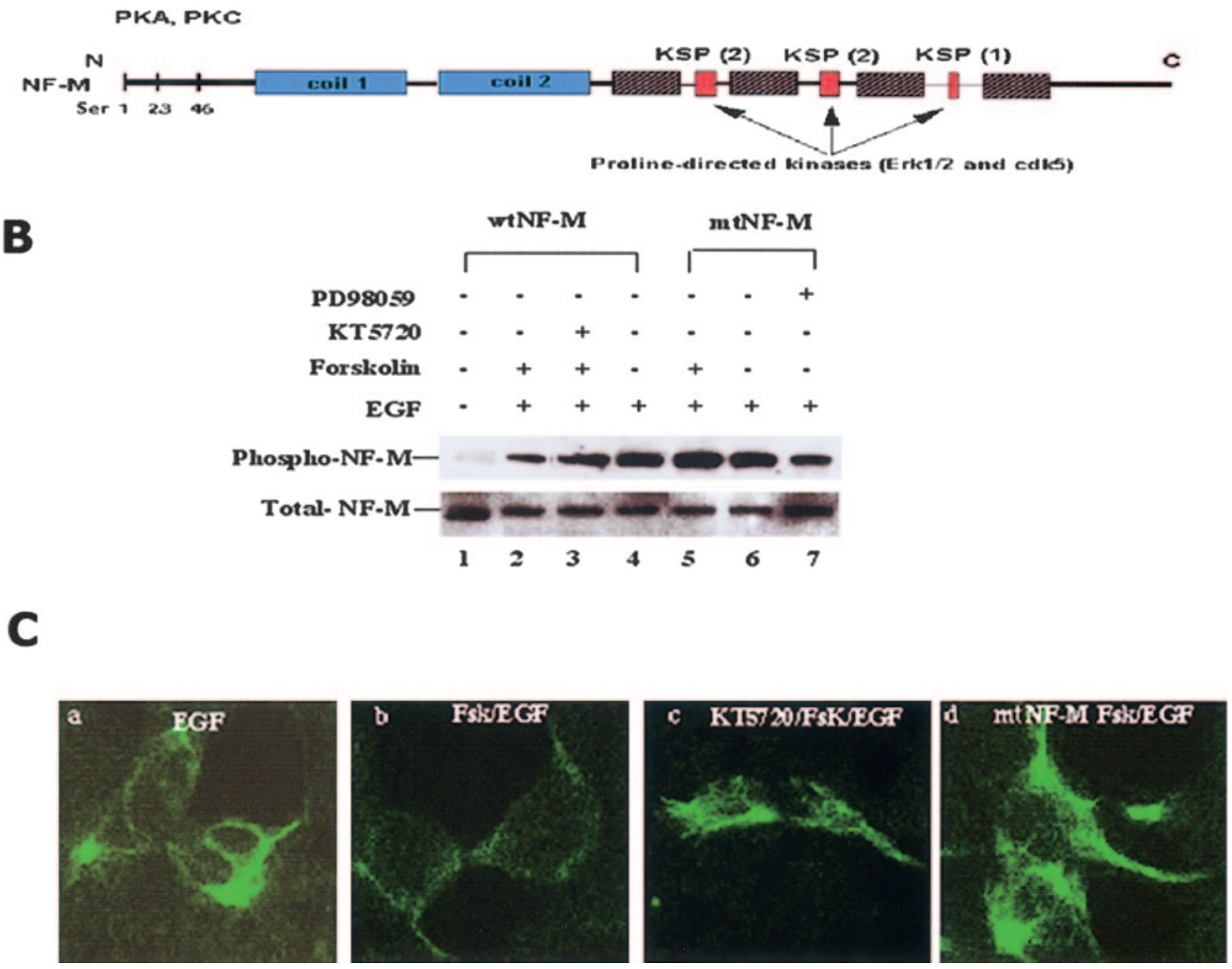

Figure 8. Test of the model. Does PKA phosphorylation of specific serine sites in the head domain of NFM inhibit phosphorylation of tail domain sites by proline-directed kinase Erk1/2? (A) Diagram of the sequence structure of NF-M showing the C-terminal tail domain KSP sites for proline-directed kinases, the N-terminal head domain PKA and PKC sites ser1, ser23, and ser46. The three serine sites were mutated to alanine (muNFM), which prevents their phosphorylation. (B) NIH3T3 cells were transiently transfected with either wild-type NF-M (wtNFM) or mutant NF-M and treated with EGF, which stimulates Erk1/2 activity and phosphorylation of wt NF-M (lane 4), as seen with an antibody specific for tail domain phosphorylated KSP sites. Prior stimulation of PKA kinase with forskolin (lane 2) inhibits NF-M phosphorylation without affecting Erk1/2 activity, suggesting that NF-M tail domain sites were made inaccessible by an intramolecular reconfiguration of NF-M. Inhibition of PKA activity with a specific inhibitor (KT5720) restores NF-M tail domain phosphorylation (lane 3). On the other hand, in response to EGF, cells transfected with the mutant NF-M exhibit levels of NF-M tail domain phosphorylation similar to that seen in wtNF-M transfected cells (lane 6), and they are completely unaffected by prior forskolin treatment and PKA activation; i.e., head domain sites are not phosphorylated (lane 5, compare to lane 2). Finally, activation of Erk1/2 is essential since an inhibitor of MEKI (PD98059), the upstream kinase that activates Erk1/2, significantly down-regulates NF-M tail domain phosphorylation (lane 7). (C) An immunocytochemical assay of the transfected cells using the same specific phosphorylated NF-M antibody illustrates the effect. (a) Transfected $3 \mathrm{~T} 3$ cells stimulated with EGF show robust expression of NF-M tail domain phosphorylation. (b) Prior treatment of transfected cells with forskolin inhibits tail domain phosphorylation. (c) Forskolin/EGF treated cells exposed to the PKA inhibitor KT5720 show normal NF-M tail domain phosphorylation, while in (d), cells transfected with the muNF-M fail to respond to forskolin pretreatment and express normal levels of NF-M tail domain phosphorylation. 
phosphorylation of KSP residues in C-terminal tail domains of mammalian NF-M (Zheng et al., 2003). When cortical neurons were treated with forskolin, which specifically activates PKA phosphorylation, the phosphorylation of endogenous NF-M tail domain was inhibited, as determined by antibodies specific for the phosphorylated tail domain epitopes (Fig. 8). Moreover, the sites of PKA phosphorylation were shown to be in the NFM head domain by transfecting NIH3T3 cells with wild-type cells and NF-M mutated at specific PKA head domain residues. Stimulation of the cells expressing the mutant NF-M with epidermal growth factor in the presence of forskolin failed to inhibit NFM tail domain phosphorylation, but did inhibit tail domain phosphorylation in wild-type transfected cells. This suggests an intramolecular model of inhibition; head domain phosphorylation, by preventing assembly of the NF polymer from oligomers, evokes conformational changes in tail domains such that they are inaccessible to prolinedirected kinases. Tail domains, in the absence of assembly, may retain a globular, collapsed structure as seen in cell body filaments. Such conformational changes could explain the formation of an inactive, cell-body-specific multimeric complex.

The mechanisms of slow and fast axon transport have been extensively studied in the squid giant fiber system (Weiss et al., 1990). Originally, it was believed that neurofilaments were transported as part of the slow transport system, along with tubulin and actin. However, recent studies of green fluorescent protein (GFP)-labeled neurofilaments transfected into neurons or injected into axoplasm have shown that axonal transport of neurofilaments is more complex than previously assumed (Galbraith et al., 1999; Prahlad et al., 2000; Wang et al., 2000; Yabe et al., 2001a,b). Apparently, both NF-M and NF-H move at fast rates followed by very long pauses, or by "fits and starts," giving the impression that most neurofilaments are stationary but a few move rapidly in bursts, in both directions. Some studies suggest that neurofilaments move as polymers, while others invoke smaller oligomers. To complicate matters, rates of transport seem to relate to the extent of tail domain phosphorylation in NF-M and NF-H (Yabe et al., 2001b). C-terminal tail phosphorylation of NF-H and sidearm formation seem to slow transport, but complete removal of the NF-H tail domain in a transfected mouse model had no apparent effect on axonal transport in the optic nerve, nor on axonal caliber in motor and sensory nerves (Rao et al., 2002). These contradictory results are difficult to explain. In neurons without NF-H tail domains, there is, however, a compensatory increase in phosphorylation of NF-M that may sustain the transport rate. We shall see later that factors interfering with NF transport may be responsible for some of the pathologies found in certain neurodegenerative disorders.

Other features of the model, such as the role of phospha- tases, are also under investigation. The complexity of the processes involved in compartmental-specific phosphorylation implies a system of interactive networks with many regulatory "nodes" at structural as well as molecular sites. Any one of these might lead to deregulation and chronic stimulation of cellular pathology, resulting in cell death.

\section{Does the Model Offer Clues as to the Factors Responsible for Some Forms of Neurodegeneration?}

Squid, to our knowledge, do not suffer neurodegeneration; perhaps they don't live long enough. Nevertheless, the giant axon of Loligo pealei has served as the generic model of neural function in most organisms, and it is likely that the underlying biochemical mechanisms are also shared. Does the model described above offer any insights into the origin of some neurodegenerative disorders that might inform a working experimental approach?

For many neurodegenerative disorders, including Alzheimer's disease (AD), amyotrophic lateral sclerosis (ALS), and Parkinson's disease (PD), one of the principal neuronal pathologies is the accumulation of abnormal aggregates and neurofibrillary tangles within the cell body; these often contain, among many other proteins, extensively phosphorylated cytoskeletal proteins, such as PHF tau in AD and NFs in ALS (Sternberger et al., 1985; Lee, 1995; Julien and Mushynski, 1998; Al-Chalabi and Miller, 2003). Evidently such accumulations are toxic to cells, which accounts for the neuronal loss that leads to memory defects and dementia. For decades, much effort has been directed to studying the factors responsible for the abnormal phosphorylation and aggregation of these elements within cell bodies. The results of this effort, according to the model above, suggest that topographic phosphorylation of cytoskeletal proteins has been deregulated.

Can our studies on the squid axon, a large motor axon, and its numerous cell bodies in the GFL provide any insights into ALS pathology? In ALS, motor neurons with somatal aggregates enriched in phosphorylated neurofilaments usually degenerate (see Fig. 1). The mechanisms underlying this pathology and the factors responsible for cell death have been intensively studied in a number of model systems (Bruijn et al., 2004). A major lead was the identification of several dominant mutations in the superoxide dismutase gene SOD1 responsible for familial-linked ALS, which represents only $10 \%$ of all ALS cases (Rosen et al., 1993; Sapp et al., 1995). The pathology and course of the disease are similar to that seen in the majority of sporadic ALS cases. The mutations result in a gain of toxic properties leading to cell death. Transgenic mouse models with these human SOD1 mutations gradually develop the weakening disease and display the characteristic abnormal motor neuron inclusions consisting of phosphorylated NF-H, SOD1, and ubiquitin, among other proteins. How 
such stable aggregates induce neuronal death is not understood, but the presence of ubiquitin suggests that abnormal proteins are in the proteosome degradation pathway. Toxic effects of such aggregates may clog proteosome pathways with abnormal proteins, or they may alter mitochondrial function, leading to apoptosis (Bruijn et al., 2004). It is not clear whether the abnormal hyperphosphorylation of NF within the cell body is the principal factor driving aggregate formation, or whether abnormally phosphorylated proteins result from conformational changes in the folding of substrates within cell bodies (Kosik and Shimura, 2005). The latter would suggest that exogenous stress factors (oxygen radicals, excitatory stress factors, toxic substances produced by the abnormal activity of the SOD1 mutant enzyme) induce subtle modifications of a cell body's multimeric phosphorylation complex, activating kinases, inactivating phosphatases, or both (Johnson et al., 1996). For example, tyrosine phosphorylation of tau can induce significant conformational changes (Fabian et al., 1994). In the model, this suggests that sites previously inaccessible to proline-directed kinases such as cdc-2 like kinases (cdk5), and MAP kinases, together with CK1, a non-proline-directed kinase (Kuret et al., 1997), may become available for aberrant hyperphosphorylation. It should be noted that abnormally activated cdk5 kinase, a principal mammalian neuronal kinase regulating a range of neuronal functions from migration during neurogenesis to mature synaptic function and neuronal survival, has been implicated in tau hyperphosphorylation and tangle formation in $\mathrm{AD}$ (Patrick et al., 1999). MAP kinase pathways, which are essential during growth and differentiation in the developing nervous system, may, when deregulated by stress, also lead to tau hyperphosphorylation and cell death (Cheung and Slack, 2004; Subramaniam et al., 2004). Abnormal aggregates and tangles found in perikarya of brain neurons in such disorders as AD, Parkinson's, or ALS are deregulated "multimeric" complexes of cytoskeletal proteins, active kinases (Erk1/2, Cdk5, GSK3, PKA), other proteins ( $\alpha$-synuclein), and ubiquitin, suggesting that some abnormal proteins within the complex are undergoing degradation (PallaresTrujillo et al., 1998).

Phosphorylated tangles and aggregates may hamper or prevent axon transport of transmitter-filled vesicles to synapses and induce cell death. It has been suggested that highly phosphorylated NFs significantly slow axonal transport: the more NF-H tail domain sites phosphorylated, the greater the delay in transport (Ackerley et al., 2003, Jung et al., 2000a,b). Moreover, two proline-directed kinases, implicated as the principal players in NF-H C-terminal tail domain phosphorylation in the squid giant axon, seem to have conflicting effects on axonal transport in mammalian neurons. On the one hand, cdk5 phosphorylation of NFs seems to block axonal transport and induce the accumulation of phosphorylated NFs within perikarya, presumably by increased pausing during transport (Ackerley et al., 2003; Shea et al., 2004). On the other hand, results from the same laboratory indicate that NF C-terminal phosphorylation by MAP kinase (Erk1/2) facilitates and regulates axonal transport (Chan et al., 2004). Each kinase seems to have opposing effects on transport, perhaps indicating differential effects on NF binding to the transport motors kinesin and dynein, altering retrograde and anterograde transport differentially. Nevertheless, the conundrum is further complicated by observations, mentioned above, that there were no effects on transport in axons transfected with "tailess" NF-H mutant subunits (Rao et al., 2002).

Significantly, studies of axonal transport in axoplasm extruded from the squid giant axon suggest that the effect of cdk5 phosphorylation may be mediated indirectly by virtue of its regulation of GSK3 activity and the kinesin motor (Morfini et al., 2004). Sustained cdk5 activity is essential for promoting kinesin-driven fast axon transport; specific inhibition of cdk5 slows transport indirectly, by activating a phosphatase PP1 that dephosphorylates and activates GSK3, which in turn, phosphorylates the kinesin motor, slowing anterograde but not retrograde transport. Since kinesin is a motor responsible for the fast transport of NFs (Yabe et al., 1999), such indirect effects on motors by deregulated proline-directed kinases may contribute to the perikaryal accumulation of aggregates by blocking axon transport.

An alternative site for deregulation may be overexpression of one or another NF subunit precursor, or deletion of an NF subunit as in NF null mice, thus disrupting subunit stoichiometry, affecting NF assembly and axon diameter or filament spacing (Elder et al., 1998; Rao et al., 1998; Zhu et al., 1998). This, too, may alter the structure of phosphorylation complexes, activating kinases and NF phosphorylation, with subsequent effects on axon transport.

Finally, stress-induced abnormalities in signal transduction pathways that down-regulate ser/thr and/or tyrosine phosphatases may disrupt the fine-tuned equilibria that tightly regulate topographic phosphorylation between cell body and axonal compartments. An increase in the number of phosphorylated sites on cytoskeletal proteins within the cell body could evoke conformational changes that result in aggregates, tangles, obstructed transport, and eventually cell death. Contrary to expectations, however, an increase of assembled NF-M and NF-H in perikarya of SOD1 mutant mice seems to ameliorate the disease, increasing life span for many months (Couillard-Despres et al., 1998). In fact, the perikaryal accumulations of hyperphosphorylated NF-H induced by a deregulated cdk5 in SOD mutant ALS mice alleviates the toxicity and improves the life span of the mice (Nguyen et al., 2001), an unexpected result in view of the presumed role of deregulated cdk5 and tau hyperphosphorylation in $\mathrm{AD}$. It is proposed that the excess $\mathrm{NF}-\mathrm{H}$, with its numerous KSP sites, acts as a sink for cdk5 activity, thereby 
reducing toxicity levels. This may, however, reflect only a short-term adaptation since neurodegeneration is a longterm process of accumulation of insults, so that an NF-H sink may eventually become a burden if it is in the wrong place. It is also possible that such conflicting results may simply reflect differences in the affected neuronal phenotypes-large motor neurons with very long, large-diameter, myelinated axons compared to the smaller pyramidal neurons of the cortex and hippocampus.

Another observation to confound our attempts to understand ALS is the demonstration that the motor neuron pathology in SOD mutant mice is not cell-autonomous but seems to depend on interactions with surrounding cells, perhaps other neurons or glia (Clement et al., 2003). When chimeric mice that included both normal and SOD mutant neurons in the same brain were used, those SOD1 neurons that were surrounded by many normal non-neuronal cells escaped the pathology and did not degenerate, while other SOD1 neurons that were surrounded by mutant neurons or nonneuronal neurons invariably degenerated. Such chimeric mutant mice survived for much longer than the ALS model mouse. Even more striking was the fact that normal neurons surrounded by SOD1 mutant neurons developed the perikaryal filamentous deposits and degenerated, evidently "infected" by the abnormal neurons. At least in these model ALS mice, glial interactions play an important role in the development of the disease. In this connection, the squid giant fiber system may offer an excellent opportunity to study glial-axonal interactions because the axoplasm can be readily separated from its glial-rich sheath, and both can be studied biochemically under various experimental conditions.

Such speculations serve primarily as working models for further experimentation. Although we do not have squid models for neurodegeneration, we do have the giant axon system which, under appropriate experimental manipulations, may be induced to undergo controlled pathologies resembling those seen in neurodegenerative disorders. These, in turn, might be more amenable to biochemical studies.

It is noteworthy that another large motor neuron system, that of the anterior bulbar cells (ABC cells) in the hindbrain of the lamprey, a most primitive vertebrate, provides another useful model for studying neuronal cytoskeletal regulation, particularly in experimentally induced neurodegeneration (Hall et al., 2000, 2001). The large ABC axons resemble the squid giant axon in that they are not myelinated. The principal, and only, NF subunit in the lamprey neurons is NF-180, which is most homologous to mammalian NF-M but has many more glutamic acid residues and only two tail domain non-KSP phosphorylation sites. Nevertheless, it forms NFs that function as they do in mammalian neurons. Here, the effects of NF sidearm extension on axon caliber are probably facilitated by the charge-charge repulsions of the glutamic acid residues instead of highly phosphorylated KSP sites. Compared to the squid giant axon system, however, lamprey $\mathrm{ABC}$ neurons are more amenable to experimental manipulation, such as direct cell body injection of NF180 to study the effect of overexpression, or transfection of $\mathrm{ABC}$ cells by injection with GFPlabeled human tau constructs to examine the time course of tau-induced neural degeneration (Hall et al., 2001). For example, in the latter study, the authors demonstrated that the earliest stages of pathology were seen in swollen distal dendrites of $\mathrm{ABC}$ neurons with accumulations of paired helical filament (PHF1) antigen expression. In time, these accumulations swept progressively into proximal dendrites, somata, and axons, accompanied by tau hyperphosphorylation and degeneration. This study could provide some details of the progressive stages of tau-induced neurodegeneration.

We see that these two unusual motor neuron systemssquid giant fibers and lamprey $\mathrm{ABC}$ neurons-offer novel experimental approaches to our efforts to understand neurodegeneration: the former biochemically, because large cell bodies can be separated from pure axoplasm; the latter because of the ease of direct experimental manipulation by transfection. It would be useful if the technology of the latter could be successfully applied to the former.

\section{Acknowledgments}

This research was supported by the Intramural Research Programs of the NIH, National Institute of Neurological Disorders and Stroke.

\section{Literature Cited}

Ackerley, S., P. Thornhill, A. J. Grierson, J. Brownlees, B. H. Anderton, P. N. Leigh, C. E. Shaw, and C. C. Miller. 2003. Neurofilament heavy chain side arm phosphorylation regulates axonal transport of neurofilaments. J. Cell Biol. 161: 489-495.

Adelman, W. J., and D. L. Gilbert. 1990. Electrophysiology and biophysics of the squid giant axon, Pp. 93-132 in Squid as Experimental Animals, D.L. Gilbert, W.J. Adelman, and J.M. Arnold eds. Plenum Press, New York.

Al-Chalabi, A., and C. C. J. Miller. 2003. Neurofilaments and neurological disease. BioEssays 25: 346-355.

Brautigan, D. L., and C. L. Shriner. 1988. Methods to distinguish various types of protein phosphatase activity. Methods Enzymol. 159: 339-346.

Brizuela, L., G. Draetta, and D. Beach. 1987. p13sucl acts in the fission yeast cell division cycle as a component of the $\mathrm{p} 34 \mathrm{cdc} 2$ protein kinase. EMBO J. 6: $3507-3514$.

Brown, A., and R. J. Lasek. 1990. The cytoskeleton of the squid giant axon, Pp. 235-302 in Squid as Experimental Animals, D.L. Gilbert, W. J. Adelman, and J. M. Arnold, eds. Plenum Press, New York.

Bruijn, L. I., T. M. Miller, and D. W. Cleveland. 2004. Unraveling the mechanisms involved in motor neuron degeneration in ALS. Аnпи. Rev. Neurosci. 27: 723-749.

Chan, W. K., A. Dickerson, D. Ortiz, A. F. Pimenta, C. M. Moran, J. Motil, S. J. Snyder, K. Malik, H. C. Pant, and T. B. Shea. 2004. Mitogen-activated protein kinase regulates neurofilament axonal transport. J. Cell Sci. 117: 4629-4642. 
Cheung, E. C., and R. S. Slack. 2004. Emerging role for ERK as a key regulator of neuronal apoptosis. Sci STKE 2004: PE45.

Clement, A. M., M. D. Nguyen, E. A. Roberts, M. L. Garcia, S. Boillee, et al. 2003. Wild-type nonneuronal cells extend survival of SOD1 mutant motor neurons in ALS mice. Science 302: 113-117.

Cohen, P. 2000. The regulation of protein function by multisite phosphorylation-a 25-year update. Trends Biochem. Sci. 25: 596-601.

Cohen, R. S., H. C. Pant, S. House, and H. Gainer. 1987. Biochemical and immunocytochemical characterization and distribution of phosphorylated and nonphosphorylated subunits of neurofilaments in squid giant axon and stellate ganglion. J. Neurosci. 7: 2056-2074.

Couillard-Despres, S., Q. Zhu, P. C. Wong, D. L. Price, D. W. Cleveland, and J. P. Julien. 1998. Protective effect of neurofilament heavy gene overexpression in motor neuron disease induced by mutant superoxide dismutase. Proc. Natl. Acad. Sci. USA 95: 9626-9630.

de Waegh, S. M., V. M. Lee, and S. T. Brady. 1992. Local modulation of neurofilament phosphorylation, axonal caliber, and slow axonal transport by myelinating Schwann cells. Cell 68: 451-463.

Dosemeci, A., and H. C. Pant. 1992. Association of cyclic-AMP-dependent protein kinase with neurofilaments. Biochem. J. 282: 477-481.

Dosemeci, A., C. C. Floyd, and H. C. Pant. 1990. Characterization of neurofilament-associated protein kinase activities from bovine spinal cord. Cell Mol. Neurobiol. 10: 369-382.

Draetta, G., L. Brizuela, J. Potashkin, and D. Beach. 1987. Identification of p34 and p13 human homologues of the cell cycle regulators of fission yeast encoded by cdc2 and suc1. Cell 50: 319-325.

Elder, G. A., V. L. Friedrich, Jr., P. Bosco, C. Kang, A. Gourov, P. H. Tu, V. M. Lee, and R. A. Lazzarini. 1998. Absence of the mid-sized neurofilament subunit decreases axonal calibers, levels of light neurofilament (NF-L), and neurofilament content. J. Cell Biol. 141: 727-739.

Fabian, H., L. Otvos, Jr., G. I. Szendrei, E. Lang, and H. H. Mantsch. 1994. Tyrosine- versus serine-phosphorylation leads to conformational changes in a synthetic tau peptide. J. Biomol. Struct. Dyn. 12: 573-579.

Faux, M. C., and J. D. Scott. 1996. More on target with protein phosphorylation: conferring specificity by location. Trends Biol. Sci. 21: $312-315$.

Fiorito, G., and R. Chichery. 1995. Lesions of the vertical lobe impair visual discrimination learning by observation in Octopus vulgaris. Neurosci. Lett. 192: 117-120.

Fiorito, G., and P. Scotto. 1992. Observational learning in Octopus vulgaris. Science 256: 545-547.

Fiorito, G., C. von Planta, and P. Scotto. 1990. Problem solving ability of Octopus vulgaris Lamarck (Mollusca, Cephalopoda). Behav. Neural Biol. 53: 217-230.

Floyd, C. C., P. Grant, P. E. Gallant, and H. C. Pant. 1991. Principal neurofilament-associated protein kinase in squid axoplasm is related to casein kinase I. J. Biol. Chem. 266: 4987-4994.

Galbraith, J. A., T. S. Reese, M. L. Schlief, and P. E. Gallant. 1999. Slow transport of unpolymerized tubulin and polymerized neurofilament in the squid giant axon. Proc. Natl. Acad. Sci. USA 96: 1158911594.

Giasson, B. I., and W. E. Mushynski. 1997. Study of proline-directed protein kinases involved in phosphorylation of the heavy neurofilament subunit. J. Neurosci. 17: 9466-9472.

Gilbert, D. L., W. J. Adelman, and J. M. Arnold. 1990. Squid as Experimental Animals. Plenum Press, New York.

Goedert, M. 1999. Filamentous nerve cell inclusions in neurodegenerative diseases: tauopathies and alpha-synucleinopathies. Philos. Trans. R. Soc. Lond. B Biol. Sci. 354: 1101-1118.

Gordon, J. A. 1991. Use of vanadate as protein-phosphotyrosine phosphatase inhibitor. Methods Enzymol. 20: 477-482.

Grant, P., and H. C. Pant. 2004. Topographic regulation of phosphor- ylation in giant neurons of the squid, Loligo pealei: role of phosphatases. J. Neurobiol. 58: 514-528.

Grant, P., M. Diggins, and H. C. Pant. 1999. Topographic regulation of cytoskeletal protein phosphorylation by multimeric complexes in the squid giant fiber system. J. Neurobiol. 40: 89-102.

Guidato, S., L. H. Tsai, J. Woodgett, and C. C. Miller. 1996. Differential cellular phosphorylation of neurofilament heavy side-arms by glycogen synthase kinase-3 and cyclin-dependent kinase-5. J. Neurochem. 66: 1698-1706.

Hall, G. F., B. Chu, S. Lee. Y. Liu, and J. Yao. 2000. The single neurofilament subunit of the lamprey forms filaments and regulates axonal caliber and neuronal size in vivo. Cell Motil. Cytoskelet. 46: $166-182$.

Hall, G. H., V. M.-Y. Lee, G. Lee, and J. Yao. 2001. Staging of neurofibrillary degeneration caused by human tau overexpression in a unique cellular model of human tauopathy. Am. J. Pathol. 158: 235246.

Hisanaga, S., and N. Hirokawa. 1990. Molecular architecture of the neurofilament. II. Reassembly process of neurofilament L protein in vitro. J. Mol. Biol. 211: 871-882.

Hodge, A. J., and W. J. Adelman, Jr. 1980. The neuroplasmic network in Loligo and Hermissenda neurons. J. Ultrastruct. Res. 70: 220-241.

Jaffe, H., P. Sharma, P. Grant, and H. Pant. 2001. Characterization of the phosphorylation sites of the squid (Loligo pealei) high-molecularweight neurofilament protein from giant axon axoplasm. J. Neurochem. 76: $1022-1031$.

Johnson, L. N., M. E. Noble, and D. J. Owen. 1996. Active and inactive protein kinases: structural basis for regulation. Cell 85: 149_ 158.

Julien, J. P., and W. E. Mushynski. 1998. Neurofilaments in health and disease. Prog. Nucleic Acid Res. Mol. Biol. 61: 1-23.

Jung, C., J. T. Yabe, S. Lee, and T. B. Shea. 2000a. Hypophosphorylated neurofilament subunits undergo axonal transport more rapidly than more extensively phosphorylated subunits in situ. Cell Motil. Cytoskelet. 47: 120-129.

Jung, C., J. T. Yabe, and T. B. Shea. 2000b. C-terminal phosphorylation of the high molecular weight neurofilament subunit correlates with decreased neurofilament axonal transport velocity. Brain Res. 856: $12-19$.

Keyse, S. M. 2000. Protein phosphatases and the regulation of mitogenactivated protein kinase signalling. Curr. Opin. Cell Biol. 12: 186-192.

Klauck, T. M., M. C. Faux, K. Labudda, L. K. Langeberg, S. Jaken, and J. D. Scott. 1996. Coordination of three signaling enzymes by AKAP79, a mammalian scaffold protein. Science 271: 1589-1592.

Kosik, K. S., and H. Shimura. 2005. Phosphorylated tau and the neurodegenerative foldopathies. Biochim. Biophys. Acta 1739: 298-310.

Kuret, J., G. S. Johnson, D. Cha, E. R. Christenson, A. J. DeMaggio, and M. F. Hoekstra. 1997. Casein kinase 1 is tightly associated with paired-helical filaments isolated from Alzheimer's disease brain. J. Neurochem. 69: 2506-2515.

Lee, V. M. 1995. Disruption of the cytoskeleton in Alzheimer's disease. Curr. Opin. Neurobiol. 5: 663-668.

Li, B.-S., Veeranna, P. Grant, and H. C. Pant. 1999. Activation of mitogen-activated protein kinases (Erk1 and Erk2) cascade results in phosphorylation of NF-M tail domains in transfected NIH 3T3 cells. Eur. J. Biochem. 262: 211-217.

Martin, R., K. Schilling, W. Fritz, and A. Giuditta. 1990. Visualization of differential neurofilament phosphorylation in the pre- and postsynaptic axoplasm of the squid giant synapse: an electron spectroscopic study. Neuroscience 37: 553-562.

Metuzals, J., and C. S. Izzard. 1969. Spatial patterns of threadlike elements in the axoplasm of the giant nerve fiber of the squid (Loligo pealii $L$.) as disclosed by differential interference microscopy and by electron microscopy. J. Cell Biol. 43: 456-479. 
Miyamoto, S., H. Teramoto, O. A. Coso, J. S. Gutkind, P. D. Burbelo, S. K. Akiyama, and K. M. Yamada. 1995. Integrin function: molecular hierarchies of cytoskeletal and signaling molecules. J. Cell Biol. 131: 791-805.

Morfini, G., G. Szebenyi, H. Brown, H. C. Pant, G. Pigino, S. DeBoer, U. Beffert, and S. T. Brady. 2004. A novel CDK5-dependent pathway for regulating GSK3 activity and kinesin-driven motility in neurons. EMBO J. 23: 2235-2245.

Nguyen, M. D., R. C. Lariviere, and J. P. Julien. 2001. Deregulation of Cdk5 in a mouse model of ALS: toxicity alleviated by perikaryal neurofilament inclusions. Neuron 30: 135-147.

Nixon, R. A., S. E. Lewis, and C. A. Marotta. 1987. Posttranslational modification of neurofilament proteins by phosphate during axoplasmic transport in retinal ganglion cell neurons. J. Neurosci. 7: 1145-1158.

Nixon, R. A., S. E. Lewis, D. Dahl, C. A. Marotta, and U. C. Drager. 1989. Early posttranslational modifications of the three neurofilament subunits in mouse retinal ganglion cells: neuronal sites and time course in relation to subunit polymerization and axonal transport. Brain Res. Mol. Brain Res. 5: 93-108.

Pallares-Trujillo, J., F. J. Lopez-Soriano, and J. M. Argiles. 1998. The involvement of the ubiquitin system in Alzheimer's disease Int. $J$. Mol. Med. 2: 3-15.

Pant, H. C., P. E. Gallant, and H. Gainer. 1986. Characterization of a cyclic nucleotide- and calcium-independent neurofilament protein kinase activity in axoplasm from the squid giant axon. J. Biol. Chem. 261: 2968-2977.

Pant, H. C., Veeranna, and P. Grant. 2000. Regulation of axonal neurofilament phosphorylation. Curr. Top. Cell. Regul. 36: 133-150.

Patrick, G. N., L. Zukerberg, M. Nikolic, S. de la Monte, P. Dikkes, and L. H. Tsai. 1999. Conversion of p35 to p25 deregulates Cdk5 activity and promotes neurodegeneration. Nature 402: 615-622.

Prahlad, V., B. T. Helfand, G. M. Langford, R. D. Vale, and R. D. Goldman. 2000. Fast transport of neurofilament protein along microtubules in squid axoplasm. J. Cell. Sci. 113: 3939-3946.

Rao, M. V., M. K. Houseweart, T. L. Williamson, T. O. Crawford, J. Folmer and D. W. Cleveland. 1998. Neurofilament-dependent radial growth of motor axons and axonal organization of neurofilaments does not require the neurofilament heavy subunit (NF-H) or its phosphorylation J. Cell Biol. 143: 171-181.

Rao, M. V., M. L. Garcia, Y. Miyazaki, T. Gotow, A. Yuan, S. Mattina, C. M. Ward, N. A. Calcutt, Y. Uchiyama, R. A. Nixon, and D. W. Cleveland. 2002. Gene replacement in mice reveals that the heavily phosphorylated tail of neurofilament heavy subunit does not affect axonal caliber or the transit of cargoes in slow axonal transport. J. Cell Biol. 158: 681-693.

Roach, P. J. 1991. Multisite and hierarchal protein phosphorylation. J. Biol. Chem. 266: 14139-14142.

Robinson, M. J., and M. H. Cobb. 1997. Mitogen-activated protein kinase pathways. Curr. Opin. Cell Biol. 9: 180-186.

Rosen, D. R., T. Siddique, D. Patterson, D. A. Figlewicz, P. Sapp, A. Hentati, D. Donaldson, J. Goto, J. P. O'Regan, H. X. Deng, et al. 1993. Mutations in $\mathrm{Cu} / \mathrm{Zn}$ superoxide dismutase gene are associated with familial amyotrophic lateral sclerosis. Nature 362: 59-62.

Sanchez, I., L. Hassinger, R. K. Sihag, D. W. Cleveland, P. Mohan, and R. A. Nixon. 2000. Local control of neurofilament accumulation during radial growth of myelinating axons in vivo: selective role of site-specific phosphorylation. J. Cell Biol. 151: 1013-1024.

Sapp, P. C., D. R. Rosen, B. A. Hosler, J. Esteban, D. McKenna-Yasek, J. P. O'Regan, H. R. Horvitz, and R. H. Brown, Jr. 1995. Identification of three novel mutations in the gene for $\mathrm{Cu} / \mathrm{Zn}$ superoxide dismutase in patients with familial amyotrophic lateral sclerosis. Neuromuscul. Disord. 5: 353-357.

Shea, T. B., J. T. Yabe, D. Ortiz, A. Pimenta, P. Loomis, R. D. Goldman, N. Amin, and H. C. Pant. 2004. Cdk5 regulates axonal transport and phosphorylation of neurofilaments in cultured neurons. J. Cell Sci. 117: 933-941.

Sihag, R. K., and R. A. Nixon. 1989. In vivo phosphorylation of distinct domains of the 70-kilodalton neurofilament subunit involves different protein kinases. J. Biol. Chem. 264: 457-464.

Sihag, R. K., and R. A. Nixon. 1990. Phosphorylation of the aminoterminal head domain of the middle molecular mass $145-\mathrm{kDa}$ subunit of neurofilaments: evidence for regulation by second messenger-dependent protein kinases. J. Biol. Chem. 265: 4166-4171.

Sihag, R. K., and R. A. Nixon. 1991. Identification of Ser-55 as a major protein kinase A phosphorylation site on the 70-kDa subunit of neurofilaments: early turnover during axonal transport. J. Biol. Chem. 266: 18861-18867.

Sihag, R. K., A. Y. Jeng, and R. A. Nixon. 1988. Phosphorylation of neurofilament proteins by protein kinase C. FEBS Lett. 233: 181-185.

Sternberger, L. A., and N. H. Sternberger. 1983. Monoclonal antibodies distinguish phosphorylated and non-phosphorylated forms of neurofilaments in situ. Proc. Natl. Acad. Sci. USA 80: 6126-6130.

Sternberger, N. H., L. A. Sternberger, and J. Ulrich. 1985. Aberrant neurofilament phosphorylation in Alzheimer disease. Proc. Natl. Acad. Sci. USA 82: 4274-4276.

Subramaniam, S., U. Zirrgiebel, O. von Bohlen und Halbach, J. Strelau, C. Laliberte, D. R. Kaplan, and K. Unsicker. 2004. ERK activation promotes neuronal degeneration predominantly through plasma membrane damage and independently of caspase-3. J. Cell Biol. 165: $357-369$.

Sun, D., C. L. Leung, and R. K. H. Liem. 1996. Phosphorylation of the high molecular weight neurofilament protein $(\mathrm{NF}-\mathrm{H})$ by $\mathrm{Cdk} 5$ and $\mathrm{p} 35$. J. Biol. Chem. 271: 14245-14251.

Szaro, B. G., H. C. Pant, J. Way, and J. Battey. 1991. Squid low molecular weight neurofilament proteins are a novel class of neurofilament protein. A nuclear lamin-like core and multiple distinct proteins formed by alternative RNA processing. J. Biol. Chem. 266: 1503515041

Takahashi, M., N. Amin, P. Grant, and H. C. Pant. 1995. P13sucl associates with a cdc2-like kinase in a multimeric cytoskeletal complex in squid axoplasm. J. Neurosci. 15: 6222-6229.

Tytell, M., H. C. Pant, H. Gainer, and W. D. Hill. 1990. Characterization of the distinctive neurofilament subunits of the soma and axon initial segments in the squid stellate ganglion. J. Neurosci. Res. 25: 153-161.

Vallano, M. L., J. R. Goldenring, R. S. Lasher, and R. J. DeLorenzo. 1986. Association of calcium/calmodulin-dependent kinase with cytoskeletal preparations: phosphorylation of tubulin, neurofilament, and microtubule associated proteins. Ann. N. Y. Acad. Sci. 466: 357-374.

Veeranna, N. D. Amin, N. G. Ahn, H. Jaffe, C. A. Winters, P. Grant, and H. C. Pant. 1998. Mitogen-activated protein kinases (Erk1,2) phosphorylate Lys-Ser-Pro (KSP) repeats in neurofilament proteins NF-H and NF-M. J. Neurosci. 18: 4008-4021.

Veeranna, K. T. Shetty, M. Takahashi, P. Grant, and H. C. Pant. 2000. Cdk5 and MAPK are associated with complexes of cytoskeletal proteins in rat brain. Brain Res. Mol. Brain Res. 76: 229-236.

Wang, L., C. L. Ho, D. Sun, R. K. Liem, and A. Brown. 2000. Rapid movement of axonal neurofilaments interrupted by prolonged pauses. Nat. Cell Biol. 2: 137-141.

Way, J., M. R. Hellmich, H. Jaffe, B. Szaro, H. C. Pant, H. Gainer, and J. Battey. 1992. A high-molecular-weight squid neurofilament protein contains a lamin-like rod domain and a tail domain with Lys-SerPro repeats. Proc. Natl. Acad. Sci. USA 89: 6963-6967.

Weiss, D. G., M. A. Meyer, and G. M. Langford. 1990. Studying axoplasmic transport by video microscopy and using the squid giant axon as a model system. Pp. 303-321 in Squid as Experimental Animals, D. L. Gilbert, W. J. Adelman, and J. M. Arnold, eds. Plenum Press, New York. 
Yabe, J. T., A. Pimenta, and T. B. Shea. 1999. Kinesin-mediated transport of neurofilament protein oligomers in growing axons. J. Cell Sci. 112 (Pt 21): 3799-3814.

Yabe, J. T., W. K. Chan, T. M. Chylinski, S. Lee, A. F. Pimenta, and T. B. Shea. 2001a. The predominant form in which neurofilament subunits undergo axonal transport varies during axonal initiation, elongation, and maturation. Cell Motil. Cytoskelet. 48: 61-83.

Yabe, J. T., T. Chylinski, F. S. Wang, A. Pimenta, S. D. Kattar, M. D. Linsley, W. K. Chan, and T. B. Shea. 2001b. Neurofilaments consist of distinct populations that can be distinguished by C-terminal phosphorylation, bundling, and axonal transport rate in growing axonal neurites. J. Neurosci. 21: 2195-2205.
Young, J. Z. 1939. Fused neurons and synaptic contacts in the giant nerve fibres of cephalopods. Philos. Trans. R. Soc. Lond. B Biol. Sci. 229: 465-503.

Zheng, Y. L., B. S. Li, Veeranna, and H. C. Pant. 2003. Phosphorylation of the head domain of neurofilament protein (NF-M): a factor regulating topographic phosphorylation of NF-M tail domain KSP sites in neurons. J. Biol. Chem. 278: 24026-24032.

Zhu, Q., M. Lindenbaum, F. Levavasseur, H. Jacomy, and J. P. Julien. 1998. Disruption of the NF-H gene increases axonal microtubule content and velocity of neurofilament transport: relief of axonopathy resulting from the toxin $\beta, \beta^{\prime}$-iminodipropionitrile. J. Cell Biol. 143: 183-193. 